International Journal of Engineering \& Technology, 7 (2.7) (2018) 394-397
International Journal of Engineering \& Technology
WPC
Website: $w$ ww.sciencepubco.com/index.php/IJET
Research Paper

\title{
Occupancy based home automation system
}

\author{
K. Naga Siva Rao ${ }^{1 *}$, Dr. K. Sreenivasa Ravi $^{2}$, P. Gopi Krishna ${ }^{3}$ \\ ${ }^{1}$ P. G. Student Dept. of E.C.S.E Koneru Lakshmaiah Education Foundation, Vaddeswaram, Guntur, Andhra Pradesh, India - 522502 \\ ${ }^{2}$ Professor Dept. of E.C.S.E Koneru Lakshmaiah Education Foundation, Vaddeswaram, Guntur, Andhra Pradesh, India - 522502 \\ ${ }^{3}$ Assistant. Professor Dept. of E.C.S.E Koneru Lakshmaiah Education Foundation, Vaddeswaram, Guntur, Andhra Pradesh, \\ India -522502 \\ *Corresponding author E-mail: nagasiva448@gmail.com
}

\begin{abstract}
Home automation is a component of "The Internet of Things". Home automation has become modernized from many decades for the purport of controlling the abode appliances. In home automation we ourselves will predefine the commands for monitoring and controlling of home electrical appliances by which the energy is utilized effectively. Predicated on personal interest and cull utilizer can give his commands for controlling. Lot of energy is consumed by the electrical appliances even though there is no occupancy in a room. Occupancy is predicated proposed home automation system through which the cessation appliances are controlled and predicated based on the occupancy. In order to detect the occupancy PIR sensor is utilized which senses the heat radiations from an object and a kineticism is detected. Bluetooth predicated Android app is used to control the appliances on personal and to discard. The proposed system is a costeffective system.
\end{abstract}

Keywords: Home Automation; Arduino; Home appliances; Bluetooth; Voice commands.

\section{Introduction}

Smart home is the term commonly utilized that integrates technology of the processors and accommodations through domestic networks to ameliorate energy efficiency and amend the quality of life. Smart House is not an incipient term for the society of science, but it is still much further away from the vision and auditory perception of people [1]. Home or building consist of many appliances such as lights, fans and other mechanical equipment which consumes energy [9]. This is due to the fact that, albeit several recent works have been made in the design of the general vision of the possible approaches of remote access for control contrivances or in cases simulating the own perspicacious house and designing the main server, the design and the implementation of a standard contrivance The remote control application of the astute home has been circumscribed to computer applications and, in some cases, to the development of mobile and web applications. [2] Smartness is the term people are looking forward now a day. As the technology develops day by day people are moving towards the technology. Astute abode is the conception of technology amendment and luxurious life. As the people are going to offices and industries on their job purposes and feeling indolent and lassitude in this diligent schedule [3]. In order to take out the indolence from the people in the world and expedite their work the concept of perspicacious home plays a paramount role.

Home automation makes the peoples life very simpler. Automation is the networking of the contrivances in the house and it is the concept of preserving the energy. The energy preserving mechanism is much auxiliary for every habitation. Imagine the world with the automation everyone feels exhilarating [4]. Home automation includes controlling all the electrical and electronic contrivances in the abode in your presence or absence. The automation concept makes the humans life much simpler. Aggregating the data of all the contrivances and making centralizing the contrivances information at one place and then controlling the contrivances is much simpler

\section{Literature review}

Many researches are going on in the society name sake of internet of things that all the appliances or devices connected together centralized and controlling all those appliances. Different authors penned their different ideologies in their research work. Rozita Teymourzadeh, Salah Addin Ahmed, Kok Wai Chan, and Mok Vee Hoong [5] proposed in their paper a home automation system using the GSM. By the short message service system controlling the home appliances takes place. In this paper the author explains that a short message service simply called the SMS is sent to the users registered mobile number to indicate the status of the appliances in home. By seeing that message any user can alert and control the home appliances like television, AC, Fan, and lights. Dhakad Kunal [6] proposed an approach for home automation in which a sensor is present which senses the data and stores or sends to the web server and then from the web server the user access the data if at all user is not in home or he is far away from home he can control the devices from the web server itself just by opening the server or web page and controlling the status of the appliances like fan, light, television and Ac to switch it off when it is switched on. This automation we can call as fully automated through the concept of internet of things. Himani Singh Dhami[7] given the smart home automation system using the Raspberry pi and a single $\mathrm{Wi}-\mathrm{Fi}$ module. An internet connectivity is required for the purpose of controlling the home appliances just a web server is present and by the $\mathrm{Wi}-\mathrm{Fi}$ we can control the devices in the home just by changing the status in the web server to turn it on and turn it off. This system is user friendly and efficient system. 
Nainsi Soni, Manish Dubey [8] presented their views on the speech recognition system of home automation. Most recent years voice recognition is also the new trend developing the present scenario. By the speech recognition the lights and other home appliances are controlled. A speech recognition system is very much effective and also provides the security to the automation system. All the systems at the developed and designed in the above literature are specific to the monitoring and controlling the appliances from a remote location.

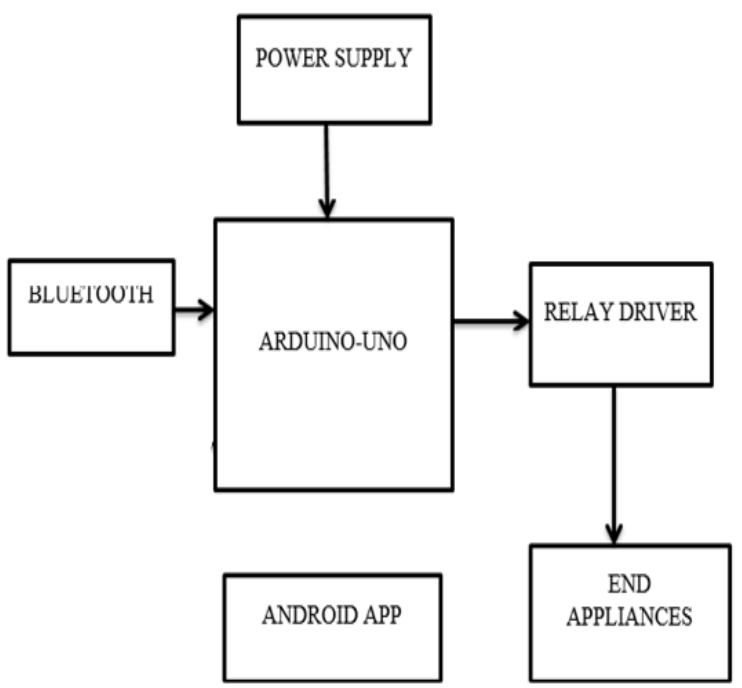

Fig. 1: Block Diagram of Existing System.

In the existing all the appliances are monitored and controlled through a mobile application or through the web server using internet. All the home appliances are monitored and controlled by connecting all the appliances by connecting them to a centra controller through relays. The central controller act as a gateway transmits the data received from the sensor to the webserver if it is connected to the internet or transmits the data to the user mobile or tab with the wireless module interfaced to the system. In the same way the central receiver receives the control commands from the remote user via internet or the wireless modules and make the devices act accordingly that are connected. These systems have a disadvantage they control the appliances according the command given by the user only or they have wait for response for notification given to the user. The central element consists of the processing element such as processor and other interfacings like sensor and wired and wireless communication modules. By utilizing the Bluetooth android app, we can send commands in the form of strings and those commands are received by the Bluetooth. The commands are decoded and according to that the loads or end appliances commenced turning ON and OFF.

\section{Architecture of proposed system}

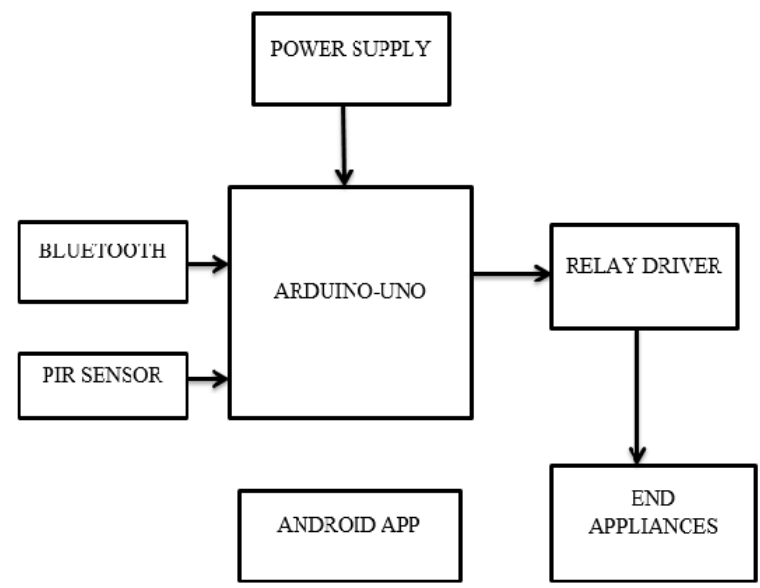

Fig. 2: Architecture of Proposed System.

In this paper an incipient system is proposed Occupancy based home automation system used to automate the habitation appliances through which the energy wastage can be reduced. The abode automation is done depending up on the detection of kineticism of living organs. Bluetooth and PIR sensor are present in the proposed system to control the appliances. Proposed system is user affable and consumes less power and additionally low cost. Depends up on the human presence that is simply called the occupancy predicated the automation takes place. That is the controlling of the appliances like television, fan, ac, light. Loads may be differing but the process of controlling is mundane for all the loads through the detection of the presence of human and then controlling via Bluetooth. The methodology, hardware and the software required for implementing the project are discussed as follows.

\section{Methodology}

The methodology, hardware, software required for the system are as follows. Hardware components required are ARDUINO-UNO board, PIR sensor, Bluetooth module, 4 channel relay and software used is ARDUINO-IDE. The brief note on each of the components required is discussed in the coming sections. ArduinoUno is a development board of embedded systems. It is a micro controller board. Atmega 328P is the controller present in the Arduino-Uno board as shown in fig 3. The controller is manufactured from Texas Instruments. It has 14 digital input output pins. Among them 6 pins are utilized as PWM pins and 6 analog pins are withal available. A quartz oscillator of $16 \mathrm{MHz}$ is additionally available on the board. Power jack is present to give the external power supply. $\mathrm{C}$ and $\mathrm{C}++$ languages are flexible to utilize for this board. Arduino coding is much simpler compare to other development boards

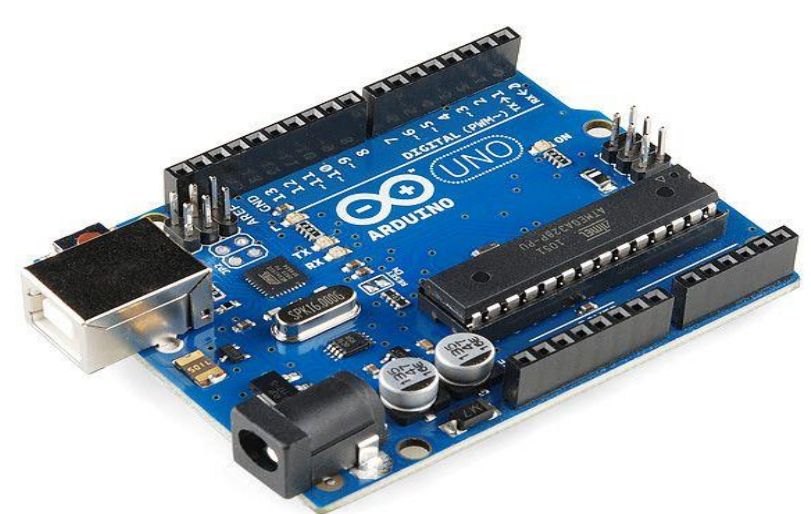

Fig. 3: Arduino. 
HC05 Bluetooth module is utilized for controlling the habitation appliances. This is only used either for transmission or for reception. This module cannot be utilized for both transmission and reception. One Bluetooth module can be connected to 7 contrivances at a time. The range of Bluetooth is 100 meters shown in fig. 4.

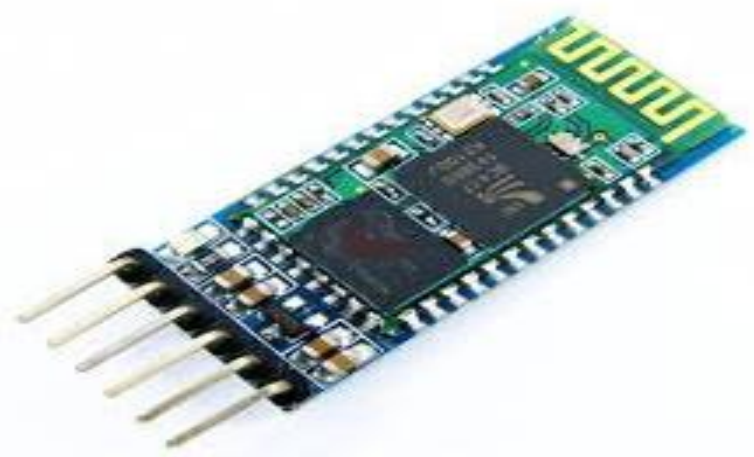

Fig. 4: Bluetooth Module.

PIR is a motion sensor. Passive infrared sensor is an electronic sensor used to sense the heat radiations emitted from the moving bodies and a motion is detected. PIR sensor in this project used for motion detection and then to control the home appliances.

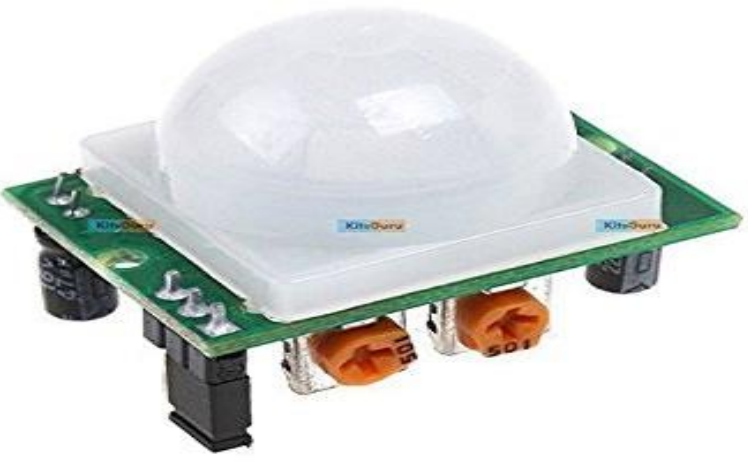

Fig. 5: PIR Sensor.

\section{Hardware implementation of the proposed architecture}

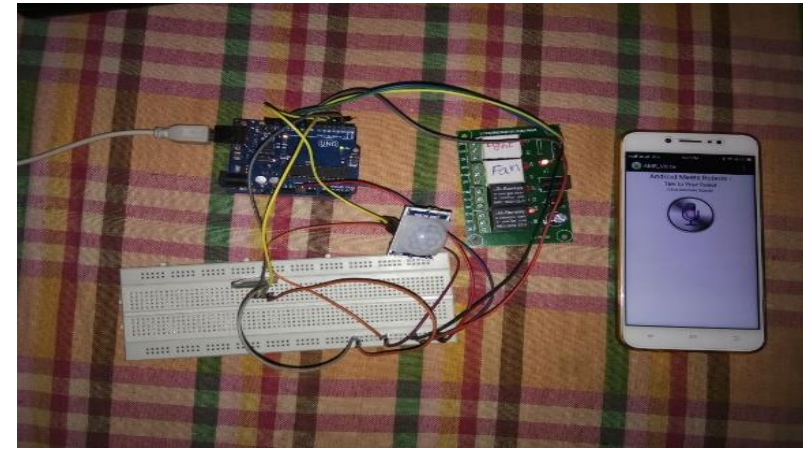

Fig. 6: Hardware Implementation of the Proposed Architecture.

Figure 6 shows the hardware implementation of the proposed architecture. Firstly, The PIR sensor is placed inside the room. Whenever the person enters the room the PIR sensor senses the heat radiation and detects the kineticism of the human being entered the room. At this moment the Bluetooth is enabled and is connected through the android predicated voice command app The utilizer now commences controlling the terminus appliances through the voice command app by giving the voice commands to the Bluetooth enabled. The Voice Command given by the utilizer to the Bluetooth module is taken by the micro controller and converted into the String format and commences verifying if string is present inside the loop that we have engendered in programming. If both the strings are matched, then the operation is commenced, and that appliance is turned ON or OFF depending upon the user's command. The predefined user commands are Turn ON Light, Turn OFF Light, so on just by adding the name of the device, by giving the voice command Turn OFF all, all the devices will be turned OFF. After some time if the person left the room then NO kineticism is detected by the PIR sensor and all the loads turned OFF automatically.

A stipulated time is mentioned in programming that if the person who left from the room enters the room after a stipulated time then the PIR detects the kineticism and the loads should have turned ON according to the anterior status of the person's cull.

If the person enters the room after excess duration, then the PIR automatically falls into RESET condition and all the loads are in OFF condition initially until the person commences voice giving voice commands on his cull.

\section{Experimental results}

The below fig. 7 shows the android voice command application before connected to Bluetooth.

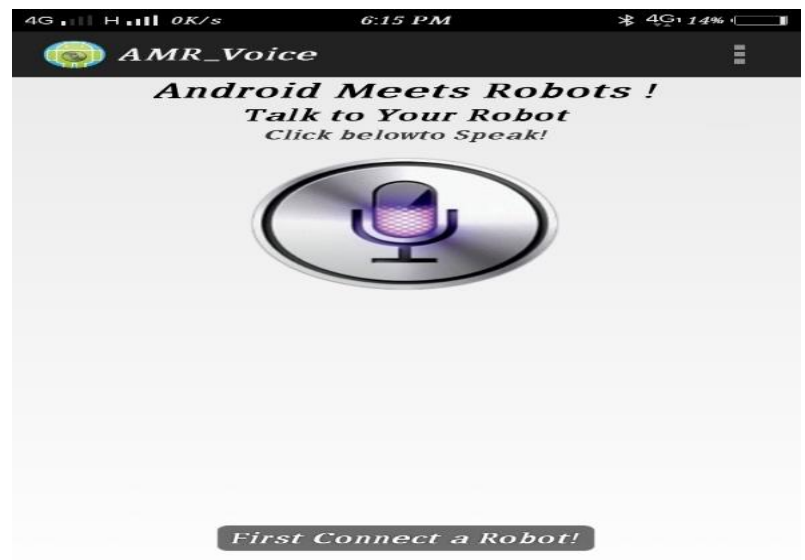

Fig. 7: Before Connecting to Bluetooth.

In order to start providing commands to the end appliances monitoring the voice command app is connected to the Bluetooth module.

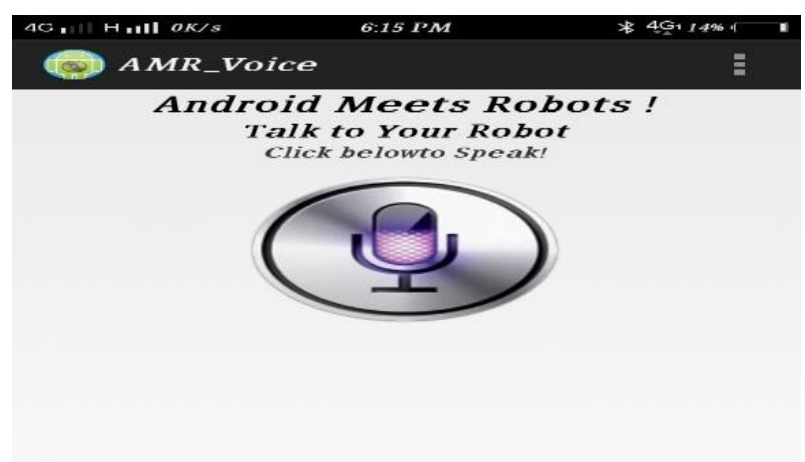

Fig. 8: After Connected to Bluetooth.

The above fig. 8 shows the Bluetooth is connected and the user can start giving commands through the voice command app.

- $\quad$ TURN ON LIGHT

- TURN OFF LIGHT

- TURN ON AC

- TURN OFF AC

- TURN ON TV

- TURN FF TV

- $\quad$ TURN ON FAN

- TURN OFF FAN 
- ALL OFF

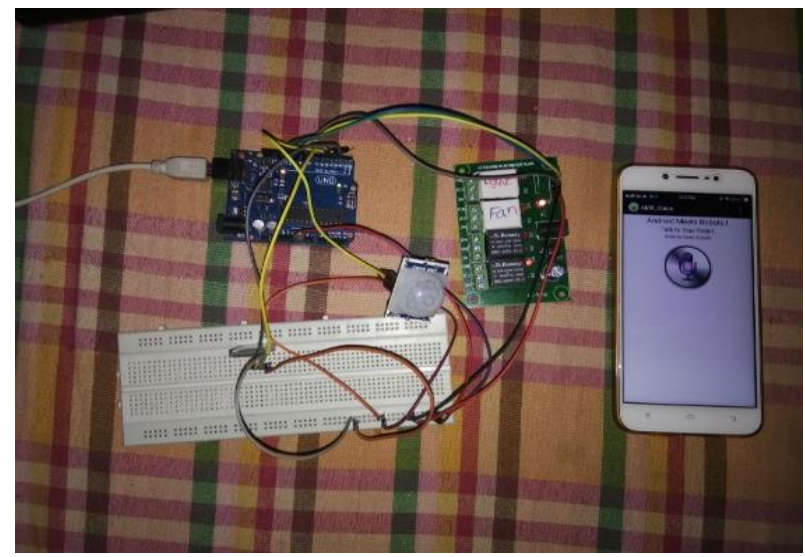

Fig. 9: All OFF Condition using Bluetooth and PIR.

The above fig. 9 shows the initial position that all loads are in OFF condition. After the motion is detected Bluetooth is activated and by the users choice monitoring of appliances takes place.

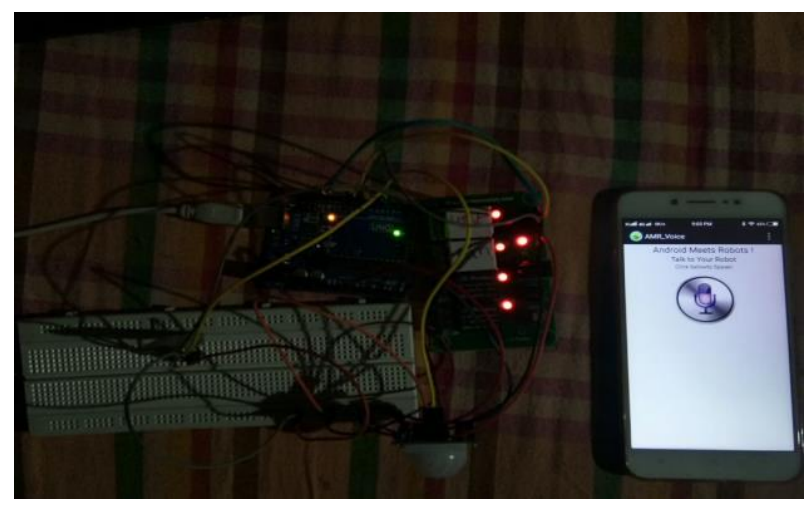

Fig. 10: All ON Condition Using Bluetooth and PIR.

The above fig. 10 shows that all the loads are in ON condition. Initially all the loads are in OFF state. The person needs all the loads to Turn ON at a time. Then he needs to send voice commands. All the loads turned ON through Bluetooth using an android app.

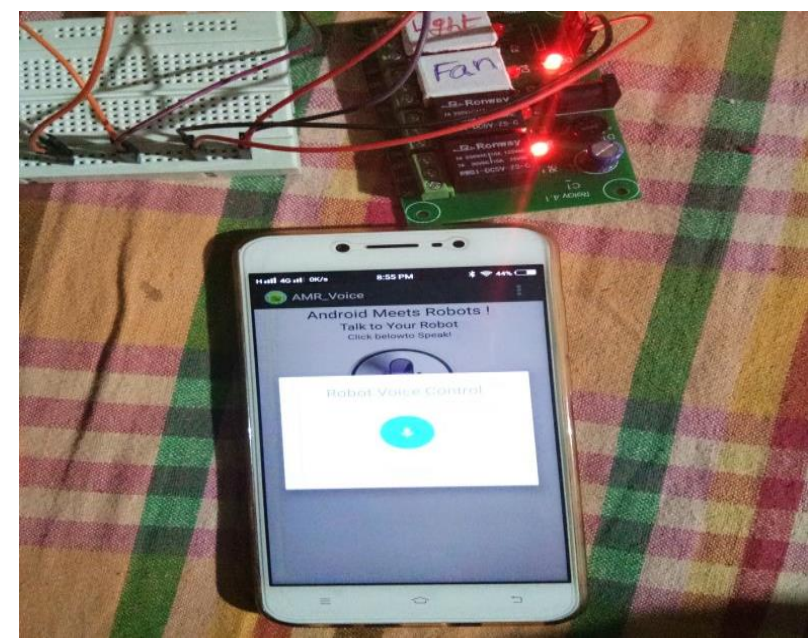

Fig. 11: ON Condition through Both Bluetooth and PIR.

The above fig. 11 shows one load is turned $\mathrm{ON}$ and the rest are in OFF condition. Initially the PIR sensor senses the heat radiations emitted by the human body and then a motion is detected. If the motion is detected by the PIR sensor then Bluetooth is enabled and the user starts providing the voice commands on his choice turned $\mathrm{ON}$.

\section{Conclusion}

The main objective of our project is to control the home appliances with smart phone and PIR sensor. In our project we have done it with Arduino-Uno development board with Arduino IDE software. Occupancy based home automation using IoT is presented. This work will be carried forward by integrating relays to Arduino-Uno development board for controlling home appliances from smart phone in a real scenario. The main working model we designed focus on home automation providing $100 \%$ efficiency.

\section{References}

[1] BarisYuksekkaya, A. AlperKayalar, M. BilgehanTosun, M. KaanOzcan, and Ali ZiyaAlkar "A GSM, Internet and Speech Controlled Wireless Interactive Home Automation System", 2006 IEEE Transactions on Consumer Electronics, Vol. 52(3) , pp. 837 . 843.

[2] S. Kumar, "Ubiquitous Smart Home System Using Android Application," International Journal of Computer Networks \& Communications, vol. 6, pp. 33-43, January 2014

[3] Milan Pandurov, Boris Petelj, Roman Pavlović, Nikola Teslić, „Platform or extending home automation gateway's functionality with plugin mechanism", The 5th IEEE International Conference on Consumer Electronics - Berlin (IEEE 2015 ICCE-Berlin).

[4] R. Piyare and M. Tazil, "Bluetooth based home automation system using cell phone," in IEEE 15th International Symposium on Consumer Electronics, Singapore, 2011, pp. 192 - 195.

[5] Rozita Teymourzadeh, CEng, Member IEEE/IET, Salah Addin Ahmed, Kok Wai Chan, and Mok Vee Hoong, "Smart GSM Based Home Automation System", IEEE Conference on systems, processes and Control, 2013.

[6] Dhakad Kunal , Dhake Tushar, Undegaonkar Pooja , Zope Vaibhav, Vinay Lodha, "Smart Home Automation Using IoT", International Journal of Advanced Research in Computer and Communication Engineering, vol5, 2016.

[7] Himani Singh Dhami, Nidhi Chandra, Nishank Srivastava, "Raspberry pi home automation using an android application", International journal of advanced research, ideas, innovations and technology, vol3, 2017.

[8] Nainsi Soni, Manish Dubey, "A Review of Home automation system using speech recognition system and machine learning", international journal of advance research in computer science and management studies, vol5, 2017.

[9] J. Kleissl and Y. Agarwal. Cyber-Physical Energy Systems: Focus on Smart Buildings. In Proceedings of the ACM/EDAC/IEEE Design Automation Conference, 2010. 